Article

\title{
A DIC-Based Study on Compressive Responses of Concrete after Exposure to Elevated Temperatures
}

\author{
Sheng Xiang, Lei Zeng *, Jicheng Zhang, Juan Chen, Yanhua Liu, Guoyuan Cheng and Jinxu Mo \\ School of Urban Construction, Yangtze University, Jingzhou 434023, China \\ * Correspondence: zenglei@yangtzeu.edu.cn; Tel.: +86-138-7235-9779
}

Received: 30 May 2019; Accepted: 23 June 2019; Published: 26 June 2019

\begin{abstract}
This paper provides an experimental investigation on the cracking process and residual mechanical properties of concrete after exposure to elevated temperatures. A total of 36 standard concrete prism specimens were tested after exposure to high temperatures of up to $600{ }^{\circ} \mathrm{C}$. The failure modes, cracking process, residual mechanical properties, deformation characteristics and the strain distribution on the surface during the loading procedure were presented. The influences of exposure temperature and water-cement ratio $(\mathrm{w} / \mathrm{c})$ were interpreted. The digital image correlation (DIC) method was applied to quantitatively and visually characterize the development of cracking and relative displacement on the concrete surface. The findings suggest that the residual compressive strength and elastic modulus of the concrete decreases gradually with the increasing temperature, especially in the specimens with lower w/c ratio. The DIC technique provides an effective means to measure very precise and detailed information, including the crack opening and distribution of strain on the concrete surface.
\end{abstract}

Keywords: digital image correlation; full-field; elevated temperature; concrete

\section{Introduction}

Concrete is one of the most widely used building materials, but it is vulnerable to explosive spalling at elevated temperatures caused by fire, explosion or furnaces nearby [1-7]. The residual mechanical properties significantly reduce after exposure [8-13]. Building fire accidents all over the globe have drawn attention to understanding residual performance at elevated temperatures. Meanwhile, mechanical properties are strongly affected by the cracks in concrete, which directly reflect the damage process and health status of concrete. Therefore, an effective method evaluating the crack propagation process and load-carrying capacity is particularly important.

In the past decades, researchers have focused on the mechanical properties of concrete after exposure to elevated temperatures, such as compressive strength, splitting tensile strength and elastic modulus. Results have indicated that the degree of deterioration depends on the peak temperature, exposure time, cooling system and concrete composition [8,9,14,15]. Omer Arioz et al. [1] carried out experimental tests to investigate concrete after exposure to elevated temperatures from $200^{\circ} \mathrm{C}$ to $1200{ }^{\circ} \mathrm{C}$. The residual compressive strength and weight losing rate had a sharp jump when the temperature of the concrete was subjected to $800^{\circ} \mathrm{C}$. The specimens completely decomposed and lost their binding properties after exposure at $1200^{\circ} \mathrm{C}$. Germán Ercolani et al. [14] explored the effects of elevated temperatures and different cooling systems on the mechanical properties of concrete. The test results revealed that the water cooling method caused serious decrease of compressive strength, while the increase of water volume used for cooling aggravated this trend. The micro-cracks of concrete at high temperatures were caused by the different thermal strains of cement matrix and aggregates. Other studies $[15,16]$ revealed that concrete made of calcareous aggregates performed better than concrete manufactured by using siliceous aggregates. Chang et al. [17] proposed a single equation for 
the complete stress-strain relationship of heated and unheated concrete. The equation was applicable to the experimental curve both in ascending and descending processes.

The research discussed above mostly focused on macro properties using traditional instruments, such as strain gauge, extensometer and displacement sensor. However, there are few studies on micro-damage research reflecting the damage process and the full field strain distribution in concrete. Recognizing the drawback of traditional measurement tools, optical measurement methods have gradually gained the attention of researchers. Holographic interference, electronic speckle interference, moiré interference and digital image correlation (DIC) are several commonly used optical measurement methods. Compared with other optical measurement methods, DIC technology has the advantages of simple optical path and insensitive to vibration. DIC technology is widely used in many fields because of its characteristics such as full-field test, simple operation and low requirement for experimental environment [18-23]. These tests are mainly done to study the complex deformation and crack development process of materials and components, which are not available in traditional measurement tools. Since concrete is a composite material composed of a mixture of various materials, the development of deformation and cracks after exposure to elevated temperatures are difficult to obtain with a displacement gauge and strain gauge. For the aim of obtaining the strain developments of the continuous cracking process and crack openings, the DIC technique is used.

In this paper, an experimental investigation on the cracking process and residual mechanical properties of concrete after exposure to elevated temperatures was carried out, and a combination of the DIC technique and mechanical test were proven as a viable approach for the health monitoring of concrete. According to the design codes (e.g., the European standard EN 1992-1-2 (2004) [24]), after exposure to $600^{\circ} \mathrm{C}$, concrete will be heavily damaged and its bearing capacity will have been reduced by more than half. In light of that, the maximum temperature of this test was taken as $600^{\circ} \mathrm{C}$. A total of 36 standard concrete prism specimens were tested after exposure to high temperatures of up to $600{ }^{\circ} \mathrm{C}$. The failure modes, cracking process, residual mechanical properties, deformation characteristics and the strain distribution on the surface during the loading procedure were presented. The influences of exposure temperature and water-cement ratio $(\mathrm{w} / \mathrm{c})$ were interpreted.

\section{Experimental Investigations}

\subsection{Test Specimens}

The guiding ideal of this experiment was to evaluate the behavior of concrete with exposure to elevated temperatures. For this purpose, 36 specimens were designed to investigate the influence of the $\mathrm{w} / \mathrm{c}$ and the peak temperature on the mechanical properties and cracking process of concrete. The specimens' variables were the w/c ratio $(0.5,0.42$ and 0.34$)$ and the exposure temperature (200, 400 and $600{ }^{\circ} \mathrm{C}$ ). The specimens were named according to their $\mathrm{w} / \mathrm{c}$ ratio and exposure temperature. For instance, C-1-200 corresponds to the mixture produced with a $0.5 \mathrm{w} / \mathrm{c}$ ratio and exposed to $200^{\circ} \mathrm{C}$. The details of specimens are shown in Table 1.

The specimens were prepared by using common ordinary Portland cement with 28 days strength of $42.5 \mathrm{MPa}$, local river sand with a fineness modulus of 2.4 and coarse aggregates with a size range of $5-10 \mathrm{~mm}$ approximately. The mix design for the concrete to be tested was determined using steps outlined in Specification for mix proportion design of ordinary concrete (JGJ55-2011) [25] and was further refined through multiple trials adjusting the mix to suit slump results. The cement and aggregates were mixed firstly. The water was then added, and the concrete was mixed for 3 min. The concrete specimens were cured for $24 \mathrm{~h}$ in plastic molds, and then were de-molded and cured in water for 28 days. To ensure moisture content stability, the specimens were air-dried in a laboratory for about 60 days before heating. 
Table 1. The details of specimens.

\begin{tabular}{ccccccc}
\hline Group & Specimen & $\begin{array}{c}\text { Coarse } \\
\text { Aggregate }\end{array}$ & Sand & Cement & $\begin{array}{c}\text { Water-Cement } \\
\text { Ratio (w/c) }\end{array}$ & $\begin{array}{c}\text { Exposure } \\
\text { Temperature }\left({ }^{\circ} \mathbf{C}\right)\end{array}$ \\
\hline \multirow{5}{*}{ C-1 } & C-1-25 & 1264 & 542 & 380 & 0.50 & 25 \\
& C-1-200 & 1264 & 542 & 380 & 0.50 & 200 \\
& C-1-400 & 1264 & 542 & 380 & 0.50 & 400 \\
& C-1-600 & 1264 & 542 & 380 & 0.50 & 600 \\
\hline \multirow{5}{*}{ C-2 } & C-2-25 & 1242 & 558 & 420 & 0.42 & 25 \\
& C-2-200 & 1242 & 558 & 420 & 0.42 & 200 \\
& C-2-400 & 1242 & 558 & 420 & 0.42 & 600 \\
& C-2-600 & 1242 & 558 & 420 & 0.42 & 25 \\
C-3 & C-3-25 & 1252 & 512 & 460 & 0.34 & 200 \\
& C-3-200 & 1252 & 512 & 460 & 0.34 & 400 \\
& C-3-400 & 1252 & 512 & 460 & 0.34 & 600 \\
\hline
\end{tabular}

\subsection{Heating Procedure and Furnace}

An electrical furnace, $80 \mathrm{~cm} \times 80 \mathrm{~cm}$ in cross section and $110 \mathrm{~cm}$ in height, was used to simulate the fire situation, as shown in Figure 1. The heating rate was $5^{\circ} \mathrm{C} / \mathrm{min}$ in this experiment, which was controlled automatically by adjusting the electric current. After heating to the target temperature $\left(200,400\right.$ and $600{ }^{\circ} \mathrm{C}$ ), the temperature was maintained for $60 \mathrm{~min}$, as shown in Figure 1 . Then, the specimens were cooled down naturally and removed from the furnace until the temperature of the furnace chamber decreased to $100{ }^{\circ} \mathrm{C}$ to avoid thermal shock caused by a large cooling rate.
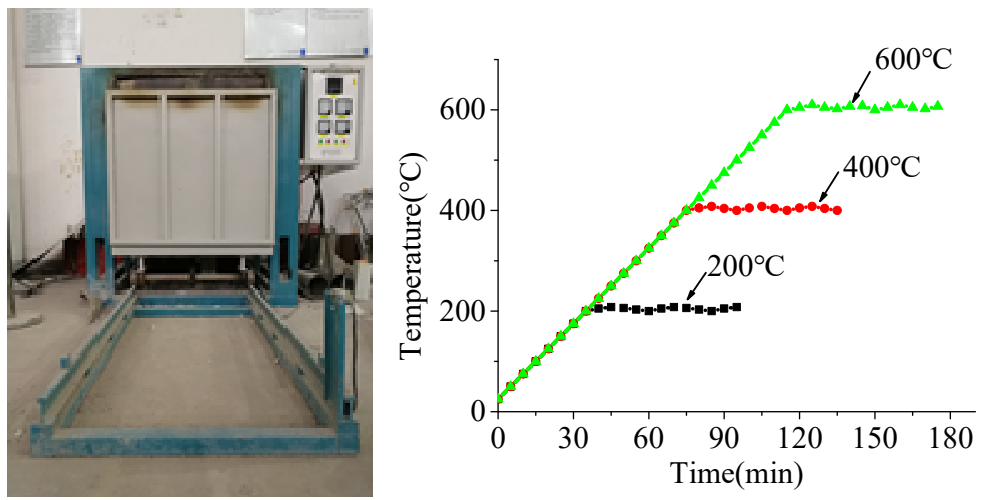

Figure 1. The electrical furnace and temperature recorded by the furnace.

\subsection{Test Setup and Procedure}

The axial compression tests on heated and unheated specimens were performed using a hydraulic press machine with a maximum ability of $5000 \mathrm{kN}$ and controlled by the actuator displacement at a rate of $0.2 \mathrm{~mm} / \mathrm{min}$ according to Standard for test method of mechanical properties on ordinary concrete (GB/T 50081-2002) [26]. A YHD displacement meter was attached on the specimen surface to measure the average strain over a $20 \mathrm{~cm}$ range in the middle of the specimen. Two strain gauges were attached to the middle of the test piece, one horizontal and the other vertical. In addition, the DIC technique was used to measure the deflections, monitor the development of cracks and detect the strain components. As shown in Figure 2, the camera was mounted on a rigid tripod and the distance between the camera and the surface of the specimen was approximately $1000 \mathrm{~mm}$. An external light source was also provided to ensure a good lighting condition. In order to provide a random gray distribution for the matching process, a random speckle pattern was applied on the surface of the specimens, as shown in Figure 2. 

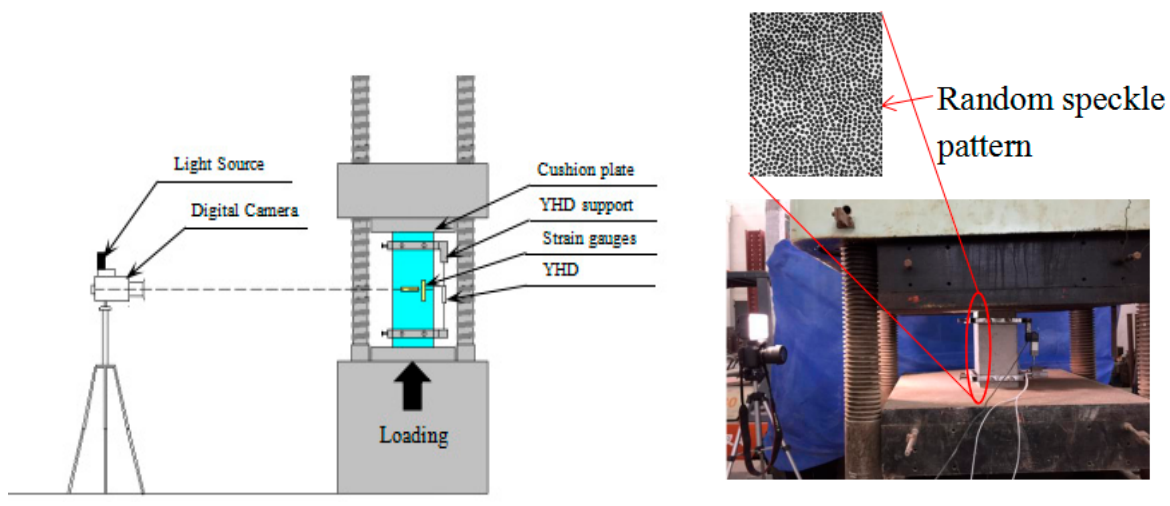

Figure 2. The testing device and instrumentations.

\subsection{DIC Principles}

DIC was originally developed by Peters and Ranson [27] from the USA and Yamaguchi [28] from Japan in the 1980s. Over the past 40 years, DIC has been developed in various aspects by many researchers over the world, and has become an effective and popular technique. During this time, Sutton and colleagues have conducted deep research on the theory and application of DIC technology, which has promoted the wide application of DIC technology [29-32]. DIC technology is an optical-numerical full-field surface displacement measurement method. It is based on a comparison between two images of the specimens coated by a random speckle pattern in the undeformed and deformed state.

The basic principle of the DIC technique is to search for a maximum correlation between small regions (called subsets or subwindows) of the specimen in the undeformed and deformed states, as illustrated in Figure 3. In order to obtain the displacements of point $P$, a square reference subset centered on point $P\left(x_{0}, y_{0}\right)$ is selected from the reference image to track its corresponding position in the deformed image. A subset of squares is chosen for matching rather than a single pixel, because the subset containing a wider variation in gray levels will distinguish itself from other subsets and can be more uniquely identified from other subsets in the deformed image [33].
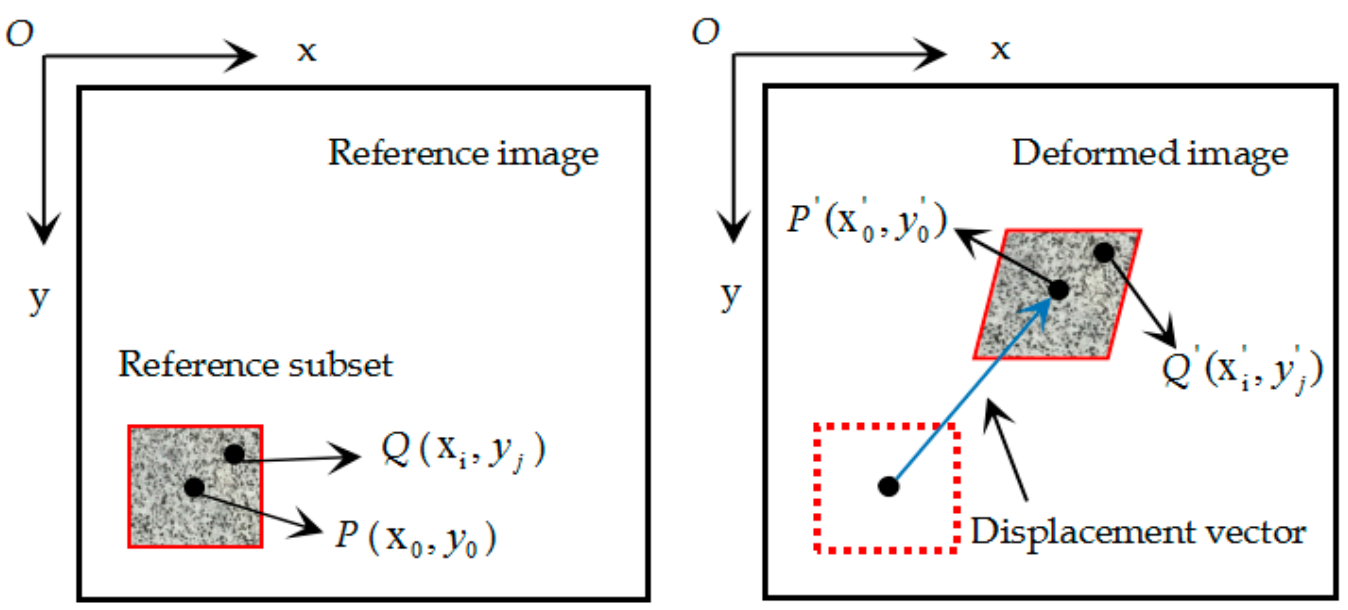

Figure 3. Schematic diagram of in-plane displacement and deformation of sub-regions.

In order to assess the similarity degree between the undeformed subset and the deformed subset, a cross-correlation (CC) criterion or sum-squared difference (SSD) correlation criterion was adopted. The matching process was conducted through searching the peak position of distribution of the correlation coefficient. When the extremum of the correlation coefficient was detected, the position of deformed subset was determined. The most popular correlation criteria include the zero-normalized cross-correlation (ZNCC) and zero-normalized sum of squared differences (ZNSSD). 
These two criterion were highly recommended for practical use, and were theoretically unaffected by changes in illumination, as they were invariant to a linear transformation in gray intensity [34,35]. The correlation criteria $C_{Z N C C}$ and $C_{Z N S S D}$ take the following form:

$$
\begin{gathered}
C_{Z N C C}=\frac{\sum_{x=-M}^{M} \sum_{y=-M}^{M}\left[f(x, y)-f_{m} \Pi g\left(x^{\prime}, y^{\prime}\right)-g_{m}\right]}{\sqrt{\sum_{x=-M}^{M} \sum_{y=-M}^{M}\left[f(x, y)-f_{m}\right]^{2}} \sqrt{\sum_{x=-M}^{M} \sum_{y=-M}^{M}\left[g\left(x^{\prime}, y^{\prime}\right)-g_{m}\right]^{2}}}, \\
C_{Z N S S D}=\sum_{x=-M}^{M} \sum_{y=-M}^{M}\left[\frac{f(x, y)-f_{m}}{\sqrt{\sum_{x=-M}^{M} \sum_{y=-M}^{M}\left[f(x, y)-f_{m}\right]^{2}}}-\frac{g\left(x^{\prime}, y^{\prime}\right)-g_{m}}{\sqrt{\sum_{x=-M}^{M} \sum_{y=-M}^{M}\left[f(x, y)-f_{m}\right]^{2}}}\right]^{2}
\end{gathered}
$$

where $f(x, y)$ is the gray value of the center point $(x, y)$ of the subset before deformation and $g\left(x^{\prime}, y^{\prime}\right)$ is the gray value of the center point $\left(x^{\prime}, y^{\prime}\right)$ of the subset after deformation. $f_{m}$ and $g_{m}$ are the average gray values of the subset before and after the deformation:

$$
\begin{aligned}
& f_{m}=\frac{1}{(2 M+1)^{2}} \sum_{x=-M}^{M} \sum_{y=-M}^{M} f(x, y), \\
& g_{m}=\frac{1}{(2 M+1)^{2}} \sum_{x=-M}^{M} \sum_{y=-M}^{M} g\left(x^{\prime}, y^{\prime}\right)
\end{aligned}
$$

It was reasonable to assume that the shape of the reference square subset was changed in the deformed image. However, based on the assumption of the deformation continuity of a deformable entity, a set of adjacent points in the reference subset were still regarded as the adjacent points in the target subset. As shown in Figure 3, the coordinates of point $Q\left(x_{i}, y_{j}\right)$ around the subset center $P\left(x_{0}, y_{0}\right)$ in the reference subset could be mapped to point $Q^{\prime}\left(x_{i}^{\prime}, y_{i}^{\prime}\right)$ in the deformed subset according to shape function. During the experiment, the rigid body translation of a subset was always accompanied with the expansion and contraction deformation, so the first-order shape function was adopted. The coordinates of point $Q^{\prime}\left(x_{i}^{\prime}, y_{j}^{\prime}\right)$ were calculated by the following shape function:

$$
\begin{aligned}
& x_{i}^{\prime}=x_{i}+\mu+\frac{\partial \mu}{\partial x} \Delta x+\frac{\partial \mu}{\partial y} \Delta y, \\
& y_{j}^{\prime}=y_{j}+v+\frac{\partial v}{\partial x} \Delta x+\frac{\partial v}{\partial y} \Delta y,
\end{aligned}
$$

where $\Delta x=x_{0}-x_{0}^{\prime}, \Delta y=y_{0}-y_{0}^{\prime}, \mu$ and $v$ are the $x$ and $y$ direction displacements of the center point of the reference facet, and $\frac{\partial \mu}{\partial x}, \frac{\partial \mu}{\partial y}, \frac{\partial v}{\partial x}$ and $\frac{\partial v}{\partial y}$ are the first-order displacement gradients.

In this test, as Figure 2 shows, images of the treated front surfaces of specimens during the compression test were taken by a digital camera with a resolution of $5472 \times 3648$ pixels. In order to avoid undesired shadows in the image, a white light was applied in this test. During the whole testing process, the frequency of the images collected by the camera was consistent with that of the YHD displacement meter recording system. The image of the sample was used as input data for the 2D-DIC software to determine the displacement of each point on it. The total area researched by DIC is equal to $150 \times 200 \mathrm{~mm}^{2}$. DIC analysis considers the subset and step size set as 51 and 9 pixels, respectively. 


\section{Experimental Results}

\subsection{Physical Properties of Concrete after Exposure to High Temperatures}

By observing the concrete surface, damage to the concrete after exposure to elevated temperatures can be roughly detected. The assessment of fire damage concrete usually begins with visual observation of color changes, cracking and spalling on the concrete surface. Figure 4 illustrates the specimens of the $\mathrm{C}-1$ group after exposure to different temperature levels $\left(200^{\circ} \mathrm{C}, 400{ }^{\circ} \mathrm{C}, 600{ }^{\circ} \mathrm{C}\right)$, along with one at ambient temperature. After exposure to $200^{\circ} \mathrm{C}$, there was no visible change in the appearance of the specimens. However, when the specimens were exposed to $400{ }^{\circ} \mathrm{C}$, some light micro cracks began to appear on the surface of the concrete, and the color of the specimens also changed to grey-white. The fine fractures were caused by the decomposition of calcium silicate hydrate (CSH) and the thermal expansion of cross aggregates. When the temperature increased to $600{ }^{\circ} \mathrm{C}$, the color of specimens turned to a slightly pink reddish color, and the cracks became more obvious. During this temperature range, calcium hydroxide $\left(\mathrm{Ca}(\mathrm{OH})_{2}\right)$ - which is the pivotal element in cement paste-decomposed and caused a dry shrinkage of the cement paste. This discoloration can be explained by the presence of iron compounds, which dehydrate or oxidize in this temperature range.

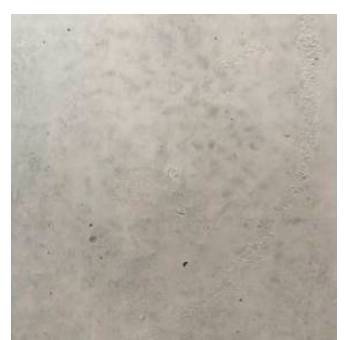

$25^{\circ} \mathrm{C}$

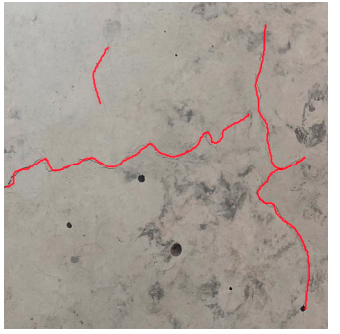

$400{ }^{\circ} \mathrm{C}$

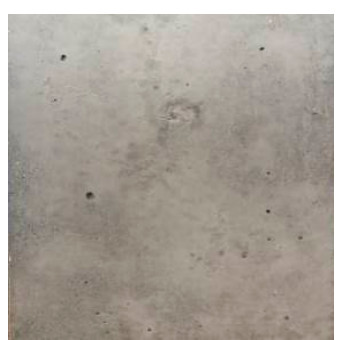

$200{ }^{\circ} \mathrm{C}$

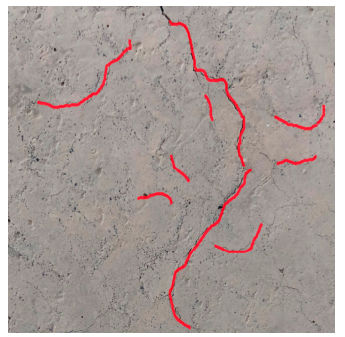

$600{ }^{\circ} \mathrm{C}$

Figure 4. Surface texture of the concrete samples exposed to different temperatures.

The spalling of concrete generally occurs when it is exposed to elevated temperatures or mixed by lower $\mathrm{w} / \mathrm{c}$ ratios. When the temperature is below $300^{\circ} \mathrm{C}$ or the $\mathrm{w} / \mathrm{c}$ ratio is higher than 0.32 , the spalling of concrete rarely occurs [36]. When subjected to elevated temperatures, many randomly distributed cracks were formed inside and on the surface of the concrete. The occurrence of spalling depends on whether the crack space is sufficient enough to release the pore pressure [37]. When the pore pressure cannot be completely released in the crack, the concrete will spall after reaching the critical strength condition [38,39]. A spalling occurred during this experiment, which can be attributed to two points. First, the w/c ratio of this specimen was just 0.34 , resulting in a denser internal structure of concrete. When exposed to an elevated temperature, it is difficult for vapor to move out from concrete into the atmosphere. The vapor pressure, which causes cracks in concrete, comes into being. When the temperature came to a certain level, the tensile stress of the concrete could not resist the pore pressure, and the spalling of concrete occurred. Another cause was that the specimen was located at the innermost part of the furnace, as shown in Figure 5. Thus, its surface temperature was higher than the other two specimens. 


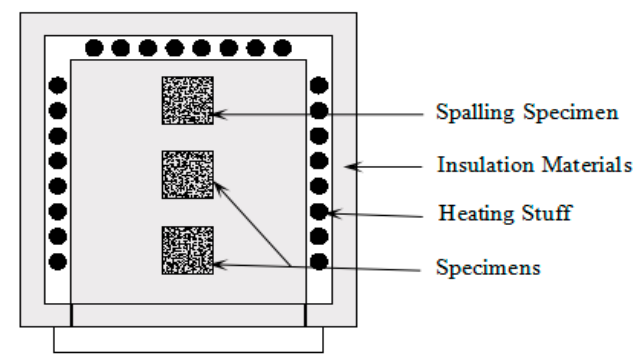

Figure 5. Section drawing of the furnace.

In order to study the effect of high temperature on the weight loss of concrete, the specimens were weighed before being placed in the furnace and after cooling to ambient temperature. The electronic scale with an accuracy of $0.1 \mathrm{~g}$ was used to weigh the specimens. Figure 6a shows the change in the weight loss of the specimens after exposure to different temperatures. When exposed to $200{ }^{\circ} \mathrm{C}$ and $600{ }^{\circ} \mathrm{C}$, the weight loss ratios were about $2 \%$ and $6 \%$, respectively, but it was shown that the largest drop in temperature was between $200{ }^{\circ} \mathrm{C}$ and $400{ }^{\circ} \mathrm{C}$. At a temperature of about $200{ }^{\circ} \mathrm{C}$, weight loss was mainly caused by the evaporation of free water in the outer part of the concrete. There was a sudden increase in weight loss at a temperature of about $400{ }^{\circ} \mathrm{C}$. When exposed to a temperature of $400^{\circ} \mathrm{C}$, the inner part of the concrete lost its free water, and the outer part of the concrete lost its chemically-bounded water. Hence, the cumulative effects of these parameters made specimens express considerable amounts of weight loss at elevated temperatures.

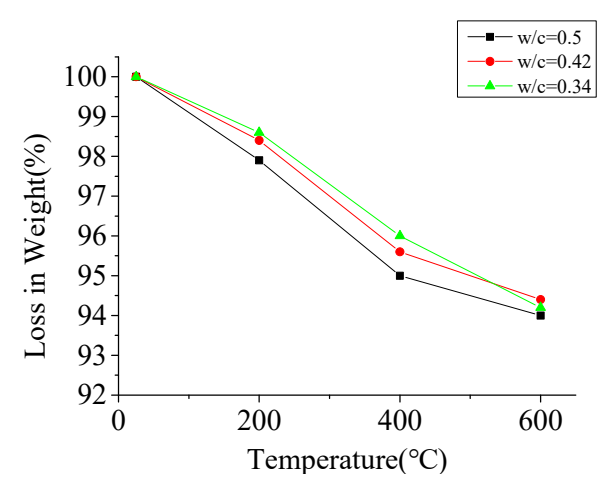

(a)

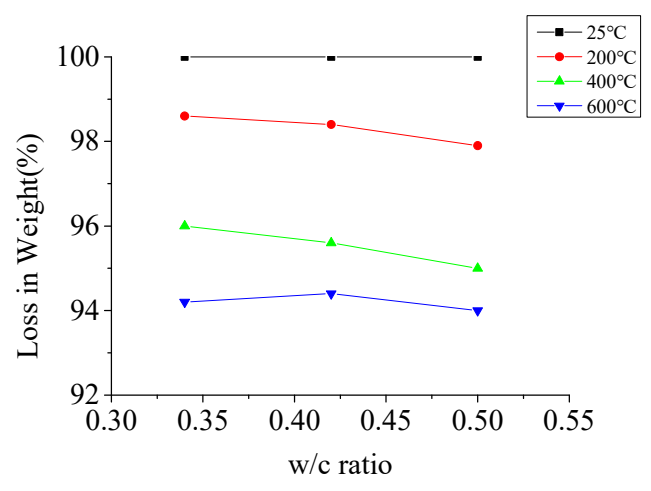

(b)

Figure 6. The weight loss of the specimens; (a) the effect of elevated temperatures on the weight loss, (b) the effect of $\mathrm{w} / \mathrm{c}$ ratio on the weight loss.

Figure $6 \mathrm{~b}$ shows the effect of the $\mathrm{w} / \mathrm{c}$ ratio on the weight loss of the concrete specimens. From Figure $6 \mathrm{~b}$ it can be observed that as the $w / c$ ratio increased, there was an increase in the percentage of weight loss within $400{ }^{\circ} \mathrm{C}$. After heating to $600{ }^{\circ} \mathrm{C}$, there were no obvious differences among the three types concretes. This can be attributed to the fact that weight loss below $400{ }^{\circ} \mathrm{C}$ is mainly due to the evaporation of water, and above $400{ }^{\circ} \mathrm{C}$ is mainly due to the decomposition of C-S-H and $\left(\mathrm{Ca}(\mathrm{OH})_{2}\right)[40]$. From the observation above, it can be found that the w/c ratio had less effect on weight loss than temperature.

\subsection{Mechanical Properties of Concrete after Exposure to High Temperatures}

\subsubsection{Failure Modes}

Failure modes of three different $\mathrm{w} / \mathrm{c}$ ratio specimens after the compressive loading are shown in Figure 7. As can be seen, the damage progression and failure mode of the specimens' exposure to elevated temperatures was different from reference specimens. 
In the case of the C-1 group, when the mechanical load reached about $70 \%$ of the peak value, cracks on the reference specimen began to appear near the top left corner. With the load increase, the cracks continued to grow, and some new, fine cracks appeared. They then developed towards the specimens' end, producing a slant crack map. At the descending stage, several small pieces of concrete peeled off. At temperatures of about $200{ }^{\circ} \mathrm{C}$ and $400{ }^{\circ} \mathrm{C}$, the effect of elevated temperature on the sequence of failure progression was not significant, except that the bearing capacity decreased slowly. When exposed to a temperature of $600{ }^{\circ} \mathrm{C}$, more fine cracks appeared on the concrete surface, and concrete spalled off at an early period. The same situation can be observed in the C-2 and C-3 groups, as shown in Figure 7.

In the case of specimen exposure to the same temperature, the damage of the lower $\mathrm{w} / \mathrm{c}$ ratio specimens were more serious. At a temperature of about $600{ }^{\circ} \mathrm{C}$, the failure modes of the C-3-600 specimen had a significant difference compared with the C-1-600 and C-2-600 specimens, as shown in the rightmost three photographs in Figure 7. These phenomena can also be observed at $200{ }^{\circ} \mathrm{C}$ and $400{ }^{\circ} \mathrm{C}$, but were not so obvious as that at $600{ }^{\circ} \mathrm{C}$. After exposure to higher temperatures, micro cracks formed along the aggregate-mortar interfaces. The damage was more obvious at lower $\mathrm{w} / \mathrm{c}$ ratio specimen, resulting in serious disintegration of the C-3 group which was cast with low w/c ratio.

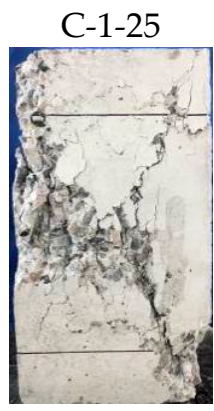

C-2-25

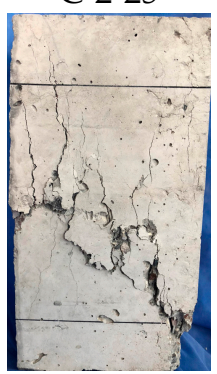

C-3-25

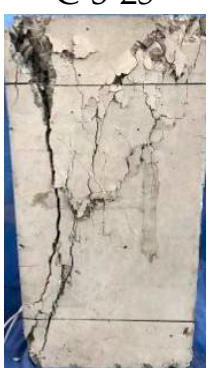

C-1-200

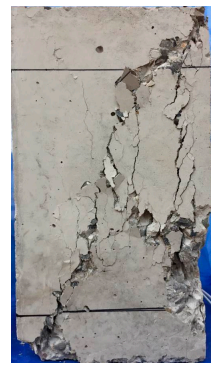

C-2-200

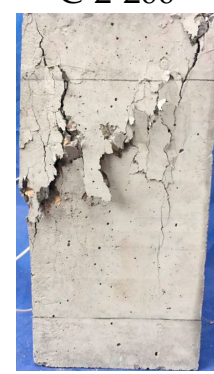

C-3-200

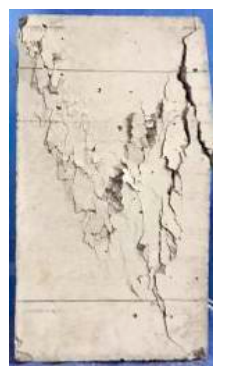

C-1-400

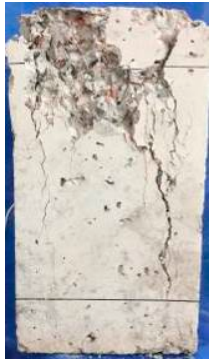

C-2-400

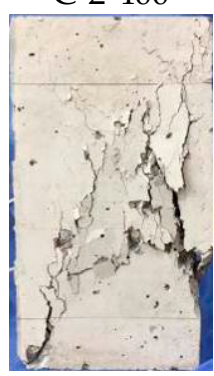

C-3-400

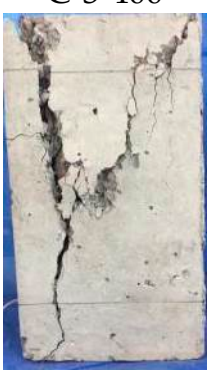

C-1-600

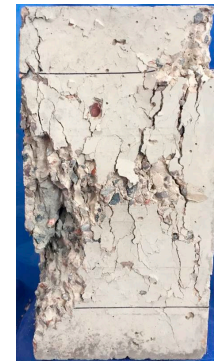

C-2-600

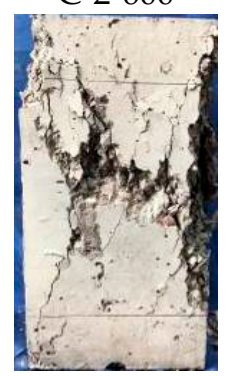

C-3-600

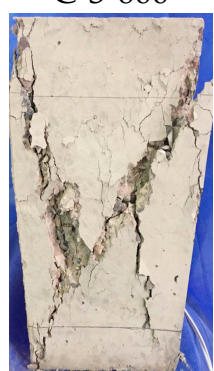

Figure 7. Failure modes of the compression test.

\subsubsection{The Results of the DIC Method}

The compressive stress-strain curves for different specimens are shown in Figure 8. The values of strain were observed from the DIC and YHD displacement meter, and the values of load were obtained from the compression testing machine. For the three types of concrete, with the temperature increase, the peak stress decreased and the corresponding peak strain increased. Factors that affect 
the stress-strain curves of concrete at elevated temperatures are the initiation and propagation of micro-cracks and the disintegration of calcium silicate hydrates. These factors caused a rapid decrease in the compression strength and a large increase in strain above $400{ }^{\circ} \mathrm{C}$.

In Figure 8, the black line represents the result of the YHD displacement meter, and the red line represents the result calculated by DIC. Out of the three samples tested, the test result of the specimen which replicated the average behavior was used for the comparison of behavior with respect to different temperatures. By comparing the results of DIC and YHD displacement meters, we found that they were in good agreement in the elastic phase, and the difference between them increased gradually with the increase of pressure at all specimens. This phenomenon was evident in group C-3, and the largest difference $(40 \%)$ in peak strain-measured by the displacement meter and DIC-occurred in this group. Because of the dense internal structure, more cracks were formed after exposure to elevated temperature, and the surface concrete was more prone to fall off during the loading process.
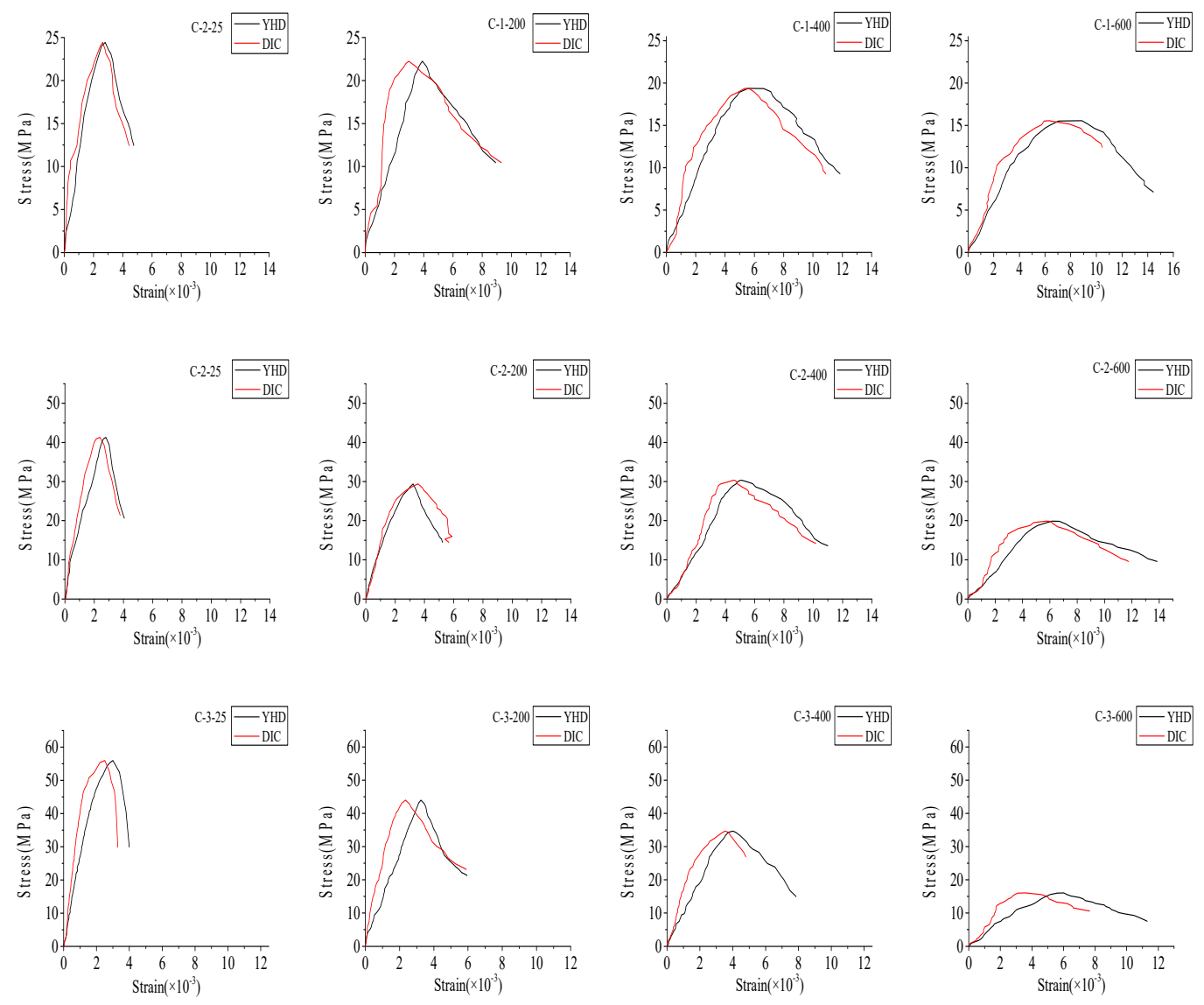

Figure 8. Stress-strain curves of specimens at different temperatures.

Figure 9 below shows the full field strain distribution of the specimen subjected to various temperatures at different load levels. From left to right, the principal strain distribution of $50 \%, 70 \%$, $90 \%, 100 \%$ and $75 \%$ (in the descending stage) of the peak bearing capacity are presented in the figure. DIC technology can obtain the strain of the specimen surface in the full-filled distribution at any stage of the loading process. When the temperature was below $400{ }^{\circ} \mathrm{C}$, the distribution of the surface strain of the concrete had obvious regularity. The DIC technique can clearly draw the high tension areas, even if no cracks were formed on the surface. With the increase of pressure, these regions gradually formed cracks and even concrete spalling. When heated to $600{ }^{\circ} \mathrm{C}$, the strain distribution on the concrete surface was sporadic. It can be seen that temperature has a serious and irreversible effect on concrete. However, the strain distribution at this region cannot be provided when the surface concrete falls off, as shown in Figure 9 for the C-3-600 specimen. This may also limit the range of application of DIC. 

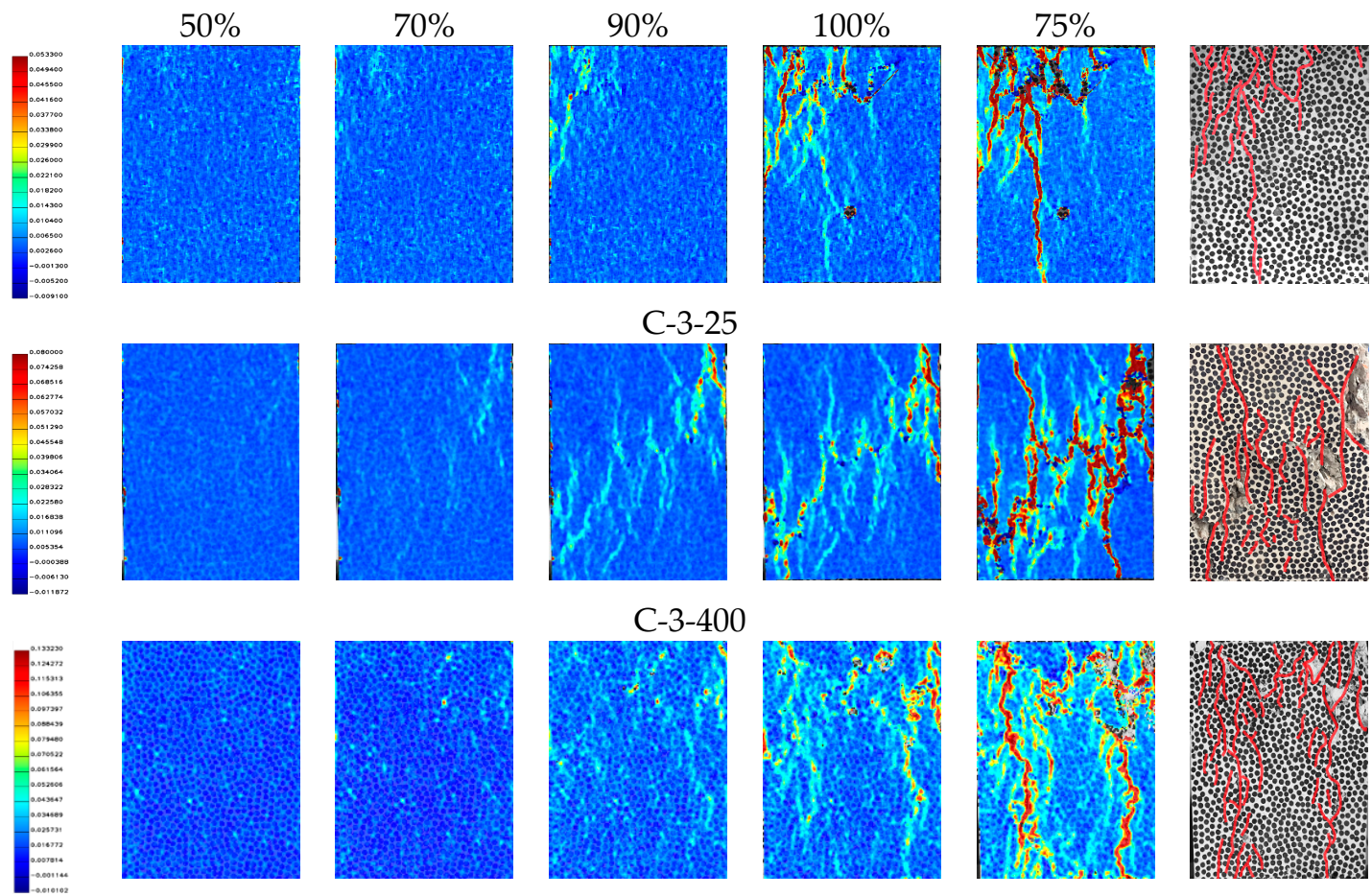

C-3-600

Figure 9. Distribution of principal strain.

\subsubsection{Residual Compressive Strength}

Figure 10a shows the effect of temperature on the compressive strength of specimens. After exposure to elevated temperature, the compressive strength of concrete decreased with the temperature increase, which could be attributed to the dehydration of concrete by the driving out of free water and fraction water of the hydration of concrete. When the temperature came to $600{ }^{\circ} \mathrm{C}$, calcium hydroxide $\left(\mathrm{Ca}(\mathrm{OH})_{2}\right)$ - which is one of the most important compounds in cement paste-decomposed, partially resulting in the shrinkage of cement paste. Cement paste is an important link between coarse aggregate, which is the strength-giving compound of concrete. As a result of the shrinkage of cement paste, many cracks were formed between coarse aggregates inside the concrete, resulting in a 50 to $70 \%$ reduction in the compressive strength of concrete. Most of the changes that concrete experiences at this temperature level are considered irreversible. It should be noted that the shrinkage of cement paste and the expansion of aggregate plays an important role in the reduction of the compressive strength of concrete after exposure to elevated temperatures.

In Figure 10a, it can be observed that the compressive strength of concrete decreased with a temperature increase, except for the C-2-400 specimen, whose residual compressive strength increased after exposure to $400{ }^{\circ} \mathrm{C}$. This situation also occurred in other studies. This can be attributed to the loss of free water in the concrete, leading to the shrinking in gel component, which enhances the bond between the cement paste and the aggregate.

Figure 10b shows the effect of the $\mathrm{w} / \mathrm{c}$ ratio on the compressive strength of specimens. When the temperature was below $400{ }^{\circ} \mathrm{C}$, the influence of the w/c ratio on the residual bearing capacity was not obvious, but it was obvious when the temperature rose to $600{ }^{\circ} \mathrm{C}$. The maximum difference of bearing capacity between specimen C-3-600 and specimen C-1-600 increased up to $18 \%$. The main reason for this phenomenon was that the low w/c ratio caused the dense microstructure of the specimen, which did not allow the release of pressure caused by evaporation of water under the elevated temperature. In this temperature range, the decomposition of calcium hydroxide $\left(\mathrm{Ca}(\mathrm{OH})_{2}\right)$ further increased the pore pressure. These factors led to a greater loss of compressive strength in specimens with smaller $\mathrm{w} / \mathrm{c}$ ratios. 


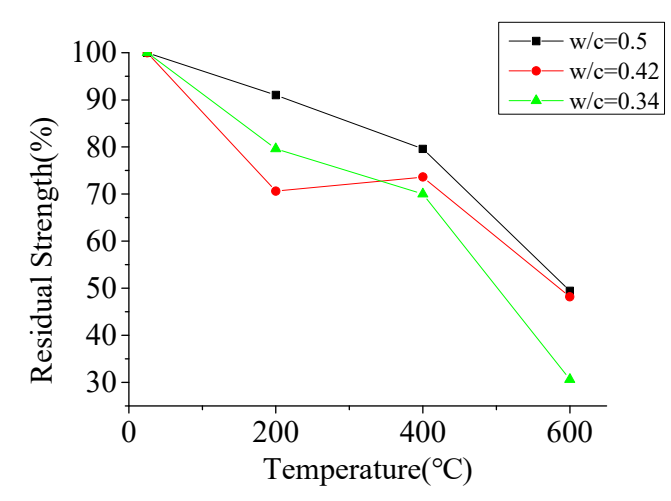

(a)

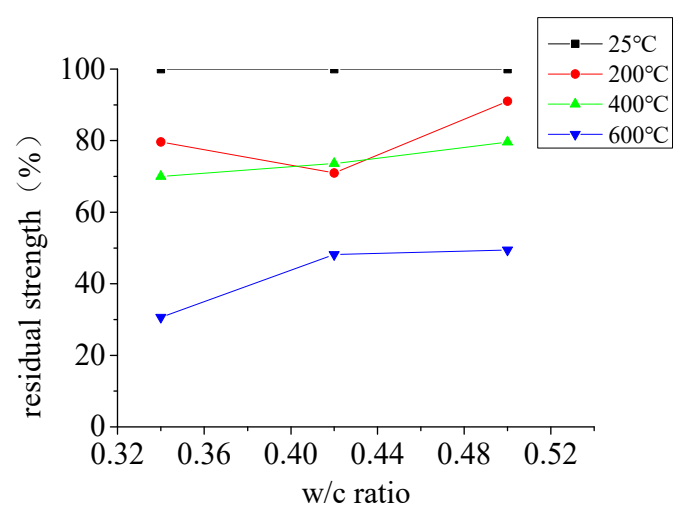

(b)

Figure 10. The residual compressive strength of specimens; (a) the effect of temperature on the compressive strength, $(\mathbf{b})$ the effect of $\mathrm{w} / \mathrm{c}$ ratio on the compressive strength.

\subsubsection{The Effect of Temperature on the Elastic Modulus}

Figure 11 shows the effect of the $\mathrm{w} / \mathrm{c}$ ratio and temperature on the elastic modulus. The values of the elastic modulus of specimens were the secant modulus at $40 \%$ of the peak stress from the experimental compressive stress-strain curve of YHD. It can be seen from Figure 11 that the trends in the loss of relative elastic modulus $\left(\mathrm{E}_{\mathrm{c}}^{\mathrm{T}} / \mathrm{E}_{\mathrm{c}}\right)$ with and increasing temperature were similar in the three different $\mathrm{w} / \mathrm{c}$ ratio specimens. When the temperature reached $600^{\circ} \mathrm{C}$, the relative elastic moduli were about $20 \%$ of the original unheated specimens. The effect of the $\mathrm{w} / \mathrm{c}$ ratio on the elastic modulus of concrete was obvious after heating to $200^{\circ} \mathrm{C}$. The different $\mathrm{w} / \mathrm{c}$ ratios resulted in different free water content, causing various void pressures at the concrete interiors under elevated temperatures, which caused many fine cracks. When the temperature reached $400{ }^{\circ} \mathrm{C}$ or above, the effect of the $\mathrm{w} / \mathrm{c}$ on the elastic modulus was not obvious. In this temperature range, the decrease in the elastic modulus was mainly due to the deterioration of the microstructure and chemical changes, which can be used to explain the above phenomenon.

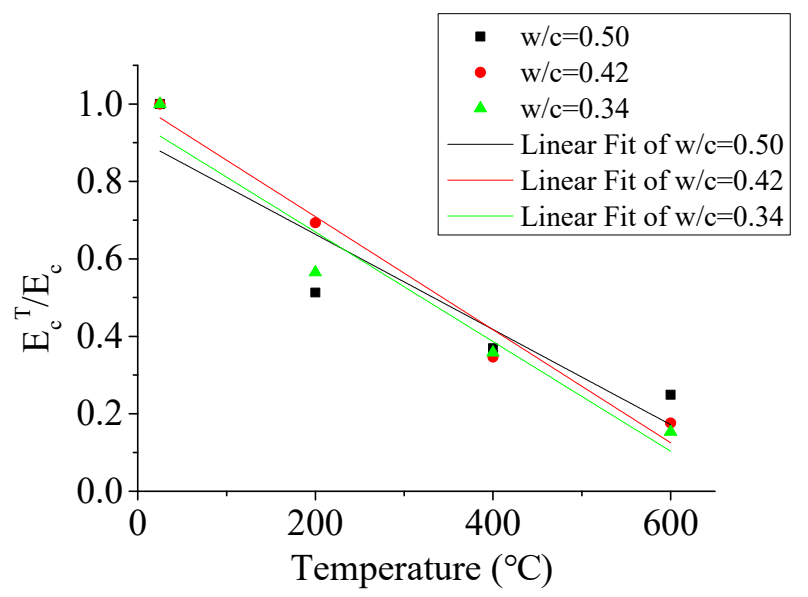

Figure 11. Elastic modulus of specimens after exposure to different temperatures.

\section{Conclusions}

The axial compression tests on ordinary concrete were carried on using a servo-hydraulic testing machine. The crack development process based on DIC technology was monitored. The following conclusions can be drawn from the experimental results of this research:

1. Concrete with different $\mathrm{w} / \mathrm{c}$ ratios present similar colors and cracking when exposed to the same temperature. The deterioration of concrete performance occurs after exposure to $400{ }^{\circ} \mathrm{C}$ or above. 
After heating to the same temperature, the specimens with low w/c ratio were easy to crack, especially beyond $400{ }^{\circ} \mathrm{C}$. As for the specimens with the same w/c ratio, with a temperature increase, concrete cracked at the early loading stage.

2. The residual compressive strength at $200{ }^{\circ} \mathrm{C}$ still retained about $85 \%$ of the original unheated value, however, the values at 400 and $600{ }^{\circ} \mathrm{C}$ reduced to $75 \%$ and $45 \%$ on average, respectively. The degeneration of compressive strength mainly occurred between $400{ }^{\circ} \mathrm{C}$ and $600{ }^{\circ} \mathrm{C}$. The decrease of compressive strength in this temperature range accounted for more than $50 \%$ of the total decrease. The effect of the w/c ratio on compressive strength was most obvious at $600{ }^{\circ} \mathrm{C}$. The effect of elevated temperature on the elastic modulus of concrete was more obvious than that on the compressive strength. After heating to $600{ }^{\circ} \mathrm{C}$, the decreased value of elastic modulus was about $80 \%$ of the control specimen.

3. In this research, the average error between the result of DIC technology and YHD displacement meter was about $14 \%$. However, from Figure 8 we can observe that the DIC technology and YHD displacement meter had a good agreement, which suggests that DIC technology was an accurate and efficient measurement tool for monitoring displacement and strain fields during the whole loading process. DIC technology can obtain multi-direction field strains on concrete surfaces, which is extremely difficult to obtain by using traditional methods. The results of DIC give an insight on how the stresses acted on concrete during the entire loading process.

Author Contributions: Investigation, S.X., Y.H.L., G.Y.C. and J.X.M.; data curation, S.X. and Y.H.L.; writing-original draft preparation, S.X.; writing-review and editing, S.X.; supervision, L.Z., J.C.Z. and J.C.; project administration, L.Z.; funding acquisition, L.Z.

Funding: The National Natural Science Foundation of China (grant number 51478080, 51278084 and 51108041).

Acknowledgments: The authors were particularly grateful for the financial support provided by the National Natural Science Foundation of China (grant number 51478080, 51278084 and 51108041).

Conflicts of Interest: The authors declare no conflict of interest.

\section{References}

1. Arioz, O. Effects of elevated temperatures on properties of concrete. Fire Safety J. 2007, 42. [CrossRef]

2. Khoury, G.A. Effect of fire on concrete and concrete structures. Progress Struct. Eng. Mater. 2010, 2, $429-447$. [CrossRef]

3. Ali, F.; Nadjai, A.; Silcock, G.; Abu-Tair, A. Outcomes of a major research on fire resistance of concrete columns. Fire Safety J. 2004, 39, 433-445. [CrossRef]

4. Zeng, L.; Seyed, M.P.; Kong, Q.Z.; Huo, L.S.; Ing, L.; Song, G.B. Bond slip detection of concrete-encased composite structure using shear wave based active sensing approach. Smart Mater. Struct. 2015, 24, 125026. [CrossRef]

5. Xiao, Y.F.; Zeng, L.; Cui, Z.K.; Jin, S.Q.; Chen, Y.G. Experimental and analytical performance evaluation of steel beam to concrete-encased composite column with unsymmetrical steel section joints. Steel Compos. Struct. 2017, 23, 17-29. [CrossRef]

6. Xiao, J.; Konig, G. Study on concrete at high temperature in China-an overview. Fire Safety J. 2004, 39, 89-103. [CrossRef]

7. Zeng, L.; Xiao, Y.F.; Chen, Y.G.; Jin, S.Q.; Xie, W.; Li, X.J. Evaluation of Concrete-Encased Steel Frame-Reinforced Concrete Core Tube Buildings Based on Dynamic Characteristics. Appl. Sci. 2017, 7, 314. [CrossRef]

8. Zeng, L.; Ren, W.T.; Zou, Z.T. Experimental study on seismic behavior of frame structures composed of concrete encased columns with L-shaped steel section and steel beams. Earthq. Struct. 2019, 16, 97-107.

9. Ma, Q.M.; Guo, R.X.; Zhao, Z.M.; Lin, Z.W.; He, K.H. Mechanical properties of concrete at high temperature-A review. Const. Building Mater. 2015, 93, 371-383. [CrossRef]

10. Novak, J.; Kohoutkova, A. Mechanical properties of concrete composites subject to elevated temperature. Fire Safety J. 2018, 95, 66-76. [CrossRef] 
11. Zhai, Y.; Li, Y.B.; Li, Y.; Jiang, W.Q.; Liu, X.Y. Research on the Impact Loading and Energy Dissipation of Concrete after Elevated Temperature under Different Heating Gradients and Cooling Methods. Materials 2018, 11, 1651. [CrossRef] [PubMed]

12. Zeng, L.; Xiao, Y.F.; Chen, J.; Chen, Y.G. Quasi-Static Cyclic Test on a Concrete-Encased Frame-Reinforced Concrete Tube Building Model. Shock Vib. 2018, 6, 1-14. [CrossRef]

13. Liang, X.W.; Wu, C.Q.; Yang, Y.K.; Li, Z.X. Experimental study on ultra-high performance concrete with high fire resistance under simultaneous effect of elevated temperature and impact loading. Cement Concr. Compos. 2019, 98, 29-38. [CrossRef]

14. Ercolani, G.; Ortega, N.F.; Priano, C.; Senas, L. Physical-mechanical behavior of concretes exposed to high temperatures and different cooling systems. Struct. Concr. 2017, 18, 487-495. [CrossRef]

15. Manita, P.; Sideris, K.K.; Savva, A. Influence of elevated temperatures on the mechanical properties of blended cement concretes prepared with limestone and siliceous aggregates. Cem. Concr. Compos. 2005, 27, 239-248.

16. Cheng, F.P.; Kodur, V.K.R.; Wang, T.C. Stress-Strain Curves for High Strength Concrete at Elevated Temperatures. J. Mater. Civil Eng. 2004, 16, 84-90. [CrossRef]

17. Chang, Y.F.; Chen, Y.H.; Sheu, M.S.; Yao, G.C. Residual stress-strain relationship for concrete after exposure to high temperatures. Cem. Concr. Res. 2006, 36, 1999-2005. [CrossRef]

18. De Wilder, K.; Lava, P.; Debruyne, D.; Wang, Y.; De Roeck, G.; Vandewalle, L. Experimental investigation on the shear capacity of prestressed concrete beams using digital image correlation. Eng. Struct. 2015, 82, 82-92. [CrossRef]

19. Gencturk, B.; Hossain, K.; Kapadia, A.; Labib, E.; Mo, Y.L. Use of digital image correlation technique in full-scale testing of prestressed concrete structures. Measurement 2014, 47, 505-515. [CrossRef]

20. Wang, Y.H.; Jiang, J.H.; Wanintrudal, C.; Du, C.; Zhou, D.; Smith, L.M.; Yang, L.X. Whole field sheet-metal tensile test using digital image correlation. Exp. Tech. 2010, 54-59. [CrossRef]

21. Jiang, J.W.; Ni, F.J.; Dong, Q.; Zhao, Y.J.; Xu, K. Fatigue Damage Model of Stone Matrix Asphalt with Polymer Modified Binder Based on Tensile Strain Evolution and Residual Strength Degradation Using Digital Image Correlation Methods. Measurement 2018, 123, 30-38. [CrossRef]

22. Srikar, G.; Anand, G.; Prakash, S.S. A Study on Residual Compression Behavior of Structural Fiber Reinforced Concrete Exposed to Moderate Temperature Using Digital Image Correlation. Inter. J. Concr. Struct Mater 2016, 10, 75-85. [CrossRef]

23. Bilotta, A.; Ceroni, F.; Lignola, G.P.; Prota, A. Use of DIC technique for investigating the behavior of FRCM materials for strengthening masonry elements. Compos. Part B 2017, 129, 251-270. [CrossRef]

24. European Standard, Eurocode 2, Design of Concrete Structures, Part 1-2. General Rules Struct. Fire Design 2004, 1992.

25. JGJ/T 240-2011. Specification for Mix Proportions Design of Ordinary Concrete; Ministry of Construction of the People's Republic of China: Beijing, China, 2011. (In Chinese)

26. GB/T 50081-2002. Standard for Test Method of Mechanical Properties on Ordinary Concrete; Ministry of Construction of the People's Republic of China: Beijing, China, 2002. (In Chinese)

27. Peters, W.H. Digital imaging technique in experimental stress analysis. Opt Eng 1982, 21, 427-431. [CrossRef]

28. Yamaguchi, I. Speckle Displacement and Decorrelation in the Diffraction and Image Fields for Small Object Deformation. Opt. Acta Inter. J. Opt. 1981, 28, 1359-1376. [CrossRef]

29. Sutton, M.A.; Cheng, M.Q.; Peters, W.H.; Chao, Y.J.; McNeill, S.R. Application of an optimized digital correlation method to planar deformation analysis. Image Vision Comput. 1986, 4, 143-150. [CrossRef]

30. Hua, T.; Xie, H.M.; Wang, S.M.; Hu, Z.X.; Chen, P.W.; Zhang, Q.M. Evaluation of the quality of a speckle pattern in the digital image correlation method by mean subset fluctuation. Opt. Laser Tech. 2011, 43, 9-13. [CrossRef]

31. Sutton, M.A.; Yan, J.H.; Tiwari, V.; Schreier, H.M.; Ortru, J. The effect of out-of-plane motion on 2D and 3D digital image correlation measurements. Opt. Lasers Eng. 2008, 46, 746-757. [CrossRef]

32. Sutton, M.A.; Hild, F. Recent Advances and Perspectives in Digital Image Correlation. Exp. Mech. 2015, 55, 1-8. [CrossRef]

33. Pan, B.; Qian, K.; Xie, H.M.; Asundi, A. Two-dimensional digital image correlation for in-plane displacement and strain measurement: A review. Meas. Sci. Tech. 2009, 20, 062001. [CrossRef] 
34. Tong, W. An Evaluation of Digital Image Correlation Criteria for Strain Mapping Applications. Strain 2005, 41, 167-175. [CrossRef]

35. Pan, B.; Xie, H.; Wang, Z. Equivalence of digital image correlation criteria for pattern matching. Appl. Opt. 2010, 49, 5501-5509. [CrossRef] [PubMed]

36. Huo, J.S.; Wang, P.; Yu, Q. Effect of water-cement ratio on mechanical behavior of concrete at elevated temperatures. J. Safety Env. 2013, 13, 199-206.

37. Mindeguia, J.C.; Hélène, C.; Pimienta, P.; Borderie, C.L. Experimental discussion on the mechanisms behind the fire spalling of concrete. Fire Mater. 2015, 39, 619-635. [CrossRef]

38. Fu, Y.F.; Wong, Y.L.; Poon, C.S.; Tang, C.A.; Lin, P. Experimental study of micro/macro crack development and stress-strain relations of cement-based composite materials at elevated temperatures. Cem. Concr. Res. 2004, 34, 789-797. [CrossRef]

39. Fu, Y.F.; Wong, Y.L.; Tang, C.A.; Poon, C.S. Thermal induced stress and associated cracking in cement-based composite at elevated temperatures-Part II: Thermal cracking around multiple inclusions. Cem. Concr. Compos. 2004, 26, 113-126. [CrossRef]

40. Behnood, A.; Ghandehari, M. Comparison of compressive and splitting tensile strength of high-strength concrete with and without polypropylene fibers heated to high temperatures. Fire Safety 2009, 44, 1015-1022. [CrossRef]

(C) 2019 by the authors. Licensee MDPI, Basel, Switzerland. This article is an open access article distributed under the terms and conditions of the Creative Commons Attribution (CC BY) license (http://creativecommons.org/licenses/by/4.0/). 